\title{
Neuroscience researches at Belyaev conference-2017
}

\author{
Yuriy L. Orlov ${ }^{1,2^{*}}$, Leonid L. Moroz ${ }^{3}$ and Ancha V. Baranova ${ }^{4,5}$ \\ From Belyaev Conference Novosibirsk, Russia. 07-10 August 2017
}

This thematic issue of $B M C$ Neuroscience continues the series of special post-conference journal issues published by BioMed Central. These Special Issues present materials from the bioinformatics and systems biology summit BGRS $\backslash S B$ (Bioinformatics of Genome Regulation and Structure/Systems Biology) held in Novosibirsk, Russia in August 2017. Here we present the works on neurobiology and computer genomics discussed in the Neuroscience section of the Belyaev Conference (http:// conf.bionet.nsc.ru/belyaev100/en). This Special Issue is accompanied by the other Special Issues collecting the works in the fields of evolutionary biology, plant biology, and genetics, which were published as BMC Evol Biol [1], and BMC Genetics [2] supplements. The Belyaev Conference-2017 was a memorial event devoted to the 100th anniversary of Academician Dmitri K. Belyaev. Evolutionary aspects of Belyaev's own works were described in $[1,3]$ and in a Special Issue of BMC Evol Biol (https:// bmcevolbiol.biomedcentral.com/articles/supplements/ volume-17-supplement-2).

The Belyaev conference-2017 continued the tradition of BGRS $\backslash$ SB by keeping several thematic sections which were run simultaneously. Previously published special issues of BMC Genomics, BMC Genetics, and BMC Evolutionary Biology covered the proceeding of the BGRS। SB-2016 conference and SBB-2016 School in Novosibirsk [4-6] as well as earlier BGRS\SB-2014 meeting (https:// bmcgenomics.biomedcentral.com/articles/supplements/ volume-15-supplement-12).

Both experimental works and the reviews on various current topics in neuroscience 2017 are put together in

\footnotetext{
${ }^{*}$ Correspondence: orlov@bionet.nsc.ru

${ }^{1}$ Novosibirsk State University, Novosibirsk, Russia

Full list of author information is available at the end of the article
}

$B M C$ Neuroscience after being presented for attendants of the Belyaev conference-2017.

The work by Polesskaya et al. [7] reviews optogenetic constructs that employ photosensitive proteins to transduce the signal and regulate gene transcription within specific sets of neurons. Optogenetics has become widely recognized for its success in real-time control of brain activity by utilizing non-mammalian photosensitive gating proteins. This type of transcriptional regulation could potentially be used to produce biological drugs in situ or on demand, by repeatedly applying light to the tissue.

Tikhonova et al. [8] discuss modulation of the expression of genes related to the metabolism of amyloid-beta. The prevailing "amyloid cascade" hypothesis about the etiology of Alzheimer's disease (AD) posit that modulating the metabolism of amyloid-beta $(A \beta)$ could be an effective strategy for the prevention and therapy of $\mathrm{AD}$. An antibiotic ceftriaxone, which possesses neuroprotective activity, also reduces both the cognitive deficits and the extent of neurodegenerative changes in OXYS rats, a recognized model for the sporadic AD. Comparison of the gene expression in tissues of untreated OXYS and Wistar rats showed a significant decrease in mRNA levels of Ace 2 in the frontal cortex and hypothalamus, and of $A c t b$ in the amygdala and points at novel targets of ceftriaxone action.

Babenko et al. [9] continues the topic of Alzheimer's disease. They present haplotype analysis of ApoE SNPs in a cohort of patients enrolled in Alzheimer Disease Neuroimaging Initiative (ADNI) and in HapMap Asian, African and European descent populations. It was found that the Asian population is the most distinct one for ApoE haplotype, with the $\mathrm{T}$ allele variant at $\mathrm{AD}$-associated $\mathrm{SNP}$ rs429358 being expanded as a protective allele during the populations divergence possibly due to the predominantly meat diet not common for primates. Haplotypic 
inference revealed an enrichment in protective alleles, including intronic SNP rs769449, in European sample. The results could be utilized for the risk assessment based on ethnic descent of an individual.

Bryzgalov et al. [10] analyzed a set of novel functional variants at the GWAS-implicated loci implicated in major depressive disorder, bipolar affective disorder and schizophrenia for their role in cognitive functions. The authors focused on regulatory genomic regions and provided important insights about fourteen regulatory SNPs located within these loci, with six of the variants unreported previously.

Follow-on series of related works in the areas of genomics, genetics discussed at "Belyaev conference-2017" and other related meetings in Novosibirsk are published in the Special Issues of BMC Evolutionary Biology (https:// bmcevolbiol.biomedcentral.com/articles/supplements/ volume-17-supplement-2), BMC Genetics (https:// bmcgenet.biomedcentral.com/articles/supplements/ volume-18-supplement-1, published at the end of 2017), BMC Genomics (https://bmcgenomics.biomedcentral. com/articles/supplements/volume-19-supplement-3), BMC Medical Genomics (https://bmcmedgenomics. biomedcentral.com/articles/supplements/volume11-supplement-1), BMC Structural Biology (https:// bmcstructbiol.biomedcentral.com/articles/supplements/ volume-18-supplement-1) (published in parallel to this issue in 2018).

The readers are welcome to visit Novosibirsk in August 2018 for XI-th BGRS\SB-2018 conference (http:// conf.bionet.nsc.ru/bgrssb2018/en/) and neurobiology sessions.

\section{Declarations}

\section{Author details}

${ }^{1}$ Novosibirsk State University, Novosibirsk, Russia. ${ }^{2}$ The A.O. Kovalevsky Institute of Marine Biological Research of RAS, Sevastopol, Russia. ${ }^{3}$ University of Florida, Gainesville, FL, USA. ${ }^{4}$ Research Centre of Medical Genetics, Moscow, Russia. ${ }^{5}$ Moscow Institute of Physics and Technology (State University), Dolgoprudnyi, Russia.

\section{About this supplement}

This article has been published as part of BMC Neuroscience Volume 19 Supplement 1, 2018: Selected articles from Belyaev Conference 2017: neuroscience. The full contents of the supplement are available online at https://bmcneurosci.biomedcentral.com/articles/supplements/volume-19-supplement-1.

\section{Authors' contributions}

$A B$ and $Y O$ are guest editors of this journal issue. $L M$ is the Conference Committee member and invited speaker. $\mathrm{YO}, \mathrm{LM}$ and $\mathrm{AB}$ wrote the manuscript. All authors read and approved the final manuscript.

\section{Acknowledgements}

The authors and guest editors acknowledge contributions of the Belyaev Conference-2017 Committee and Neurosciences Section-Academicians Nikolay A. Kolchanov, Lubomir I. Aftanas, Mikhail I. Voevoda, Tamara G. Amstislavskaya as well as the local conference committee members. The conference work was supported by the Ministry of Education and Science of the Russian Federation Grant \#14.W03.31.0015. The guest editors of the special issue are grateful to the reviewers who helped in the articles editing and issue preparation: Ming Chen (Zhejiang University, Hangzhou, China), Piramanayagam Shanmughavel (Bharathiar University, Coimbatore, India), Tatiana Tatarinova (University of La Verne, CA, USA), Alexei Tovmash (Karpov Institute of Physical Chemistry, Moscow, Russia), Anastasia Anashkina (Engelhardt Institute of Molecular Biology RAS, Moscow, Russia), Chih-Li Lin (Chung Shan Medical University, Taiwan), Chun Xu (University of Texas Rio Grande Valley, USA), Evgeniya Omelina (Institute of Molecular Cell Biology SB RAS, Novosibirsk, Russia), Jose Fernando Maya-Vetencourt (Instituto Italiano di Tecnologia, Genova, Italy), Mikhail Pletnikov (The Johns Hopkins University School of Medicine, USA), Mohammed Elanbari (Sidra Hospital, Qatar), Natalia Nalivaeva (University of Leeds, UK), Svetlana Ivanova (Tomsk National Research Medical Center of the RAS, Tomsk, Russia).

\section{Competing interests}

The authors declare that they have no competing interests.

\section{Publisher's Note}

Springer Nature remains neutral with regard to jurisdictional claims in published maps and institutional affiliations.

Published: 19 April 2018

\section{References}

1. Orlov YL, Baranova AV, Herbeck YE. Evolutionary biology at Belyaev conference-2017. BMC Evol Biol. 2017;17(Suppl 2):260. https://doi. org/10.1186/s12862-017-1102-0.

2. Orlov YL, Baranova AV, Tatarinova TV, Kolchanov NA. Genetics at Belyaev conference-2017: introductory note. BMC Genet. 2017;18(Suppl 1):116. https://doi.org/10.1186/s12863-017-0577-4.

3. Shumny VK. To the centenary of the birth of outstanding evolutionist Dmitri Konstantinovich Belyaev. Vavilovskii Zhurnal Genetiki i Selektsii=Vavilov. J Genet Breed. 2017;21(4):387-91. doi:https://doi. org/10.18699/NJ17.256 (In Russian).

4. Baranova AV, Orlov YL. The papers presented at 7th Young Scientists School "Systems Biology and Bioinformatics" (SBB'15): introductory note. BMC Genet. 2016;17(Suppl 1):S20. doi:https://doi.org/10.1186/ s12863-015-0326-5.

5. Orlov YL, Baranova AV, Hofestädt R, Kolchanov NA. Computational genomics at BGRSISB-2016: introductory note. BMC Genom. 2016;17(Suppl 14):996. https://doi.org/10.1186/s12864-016-3350-6.

6. Baranova AV, Orlov YL. Evolutionary biology at BGRSISB-2016. BMC Evol Biol. 2017;17(Suppl 1):21. https://doi.org/10.1186/s12862-016-0869-8.

7. Polesskaya O, Baranova A, Bui S, Kondratev N, Kananykhina E, Nazarenko O, Shapiro T, Nardia FB, Kornienko V, Chandhoke V, Stadler I, Lanzafame $\mathrm{R}$, Myakishev-Rempel M. Optogenetic regulation of transcription. BMC Neurosci. 2018;19(Suppl 1). https://doi.org/10.1186/s12868-018-0411-6.

8. Tikhonova MA., Amstislavskaya TG, Belichenko VM, Fedoseeva LA, Kovalenko SP, Pisareva EE, Avdeeva AS, Kolosova NG, Belyaev ND, Aftanas LI. Modulation of the expression of genes related to the system of amyloidbeta metabolism in the brain as a novel mechanism of ceftriaxone neuroprotective properties. BMC Neurosci. 2018;19(Suppl 1). https://doi. org/10.1186/s12868-018-0412-5.

9. Babenko VN, Afonnikov DV, Ignatieva EN, Klimov AV, Gusev FE, Rogaev El. Haplotype analysis of APOE intragenic SNPS. BMC Neurosci. 2018;19(Suppl 1). https://doi.org/10.1186/s12868-018-0413-4.

10. Bryzgalov LO, Korbolina EE, Brusentsov II, Leberfarb EY, Bondar NP, Merkulova TI. Novel functional variants at the GWAS-implicated loci might confer risk to major depressive disorder, bipolar affective disorder and schizophrenia. BMC Neurosci. 2018;19(Suppl 1). https://doi.org/10.1186/ s12868-018-0414-3. 